\title{
Aplastic and hypoplastic episodes in sickle cell disease and thalassaemia intermedia
}

\section{ALISON I BROWNELL,* DA McSWIGGAN, $†$ WD CUBITT, $\ddagger$ MJ ANDERSON§}

From the ${ }^{*}$ Departments of Haematology and $†$ Microbiology, Central Middlesex Hospital, the $\ddagger$ Department of Medical Microbiology, University College, and the §Middlesex Hospital Medical School, London

SUMmARY Aplastic and hypoplastic crises are well recognised complications of sickle cell disease. Recent evidence has shown that most of these crises are caused by parvovirus infection. Five cases of aplastic or hypoplastic crises in patients born and living in this country were studied. Three patients had clear evidence of parvovirus infection, while in two evidence of parvovirus infection was lacking. One patient had evidence of concurrent parvovirus and Mycoplasma pneumoniae infection. Recurrent crises may occur, and reticulocyte monitoring during infection in patients with chronic haemolytic states is therefore important.

Aplastic and hypoplastic crises are well recognised complications of patients with erythroid hyperplasia due to congenital haemolytic anaemias and haemoglobinopathies. Reports that an aplastic crisis was an apparently unique event in patients with haemolytic anaemia and that the incidence of crises in cases tended to occur in clusters, suggested that a single infecting agent might be responsible for initiating the aplastic crisis. Nevertheless, various microbial agents have been reported in association with aplastic crisis. Recently, however, Pattison et al ${ }^{12}$ showed the close association of parvovirus with aplastic crisis and, consequently, considerable doubt has been thrown on the validity of previous reports of aetiological agents. It has been suggested, therefore, that parvovirus infection may be the unique prelude to this haematological phenomenon. ${ }^{3}$ We describe five cases of aplastic and hypoplastic crises in patients with sickle cell anaemia and discuss the aetiology. These cases occurred during the last four years in a relatively stable population of 200 patients with sickle cell disease and 20 with other haemoglobinopathies.

\section{Case reports}

\section{CASE 1}

A thirteen year old boy with known $\mathrm{Hb}$ SS disease was admitted to hospital with a 24 hour history of generalised pain (including abdomen and limbs) and fever. On examination he was febrile and jaundiced with slight left hypochondrial tenderness. Hepato- splenomegaly was absent. His haemoglobin concentration, which was usually $7.0 \mathrm{~g} / \mathrm{dl}$, was $7.5 \mathrm{~g} / \mathrm{dl}$ and reticulocyte count, usually $12 \%$, was $7 \%$. After admission he remained febrile for several days. His haemoglobin concentration fell to $5 \mathrm{~g} / \mathrm{dl}$ and his reticulocyte count to zero (Fig. 1). He was transfused and subsequently made an uneventful recovery. No obvious infecting agent was found in spite of extensive bacterial and virological investigations. Parvovirus was detected by electronmicroscopy in blood taken during the aplastic crisis (Fig. 2). All other extensive bacteriological and virological investigations yielded negative results.

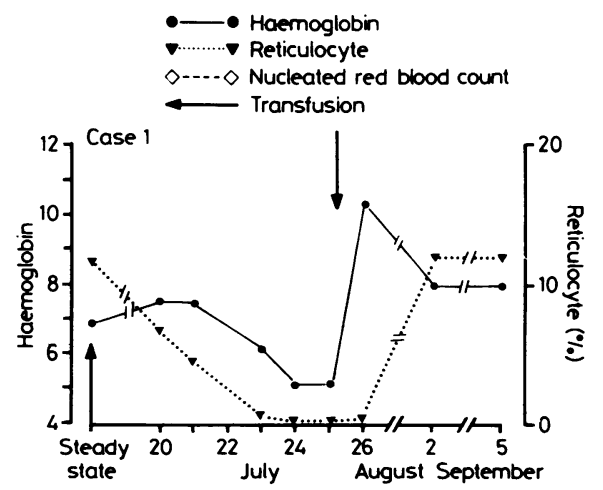

Fig. 1 Case 1. Changes in haemoglobin and reticulocyte profile during aplastic crisis.

CASE 2

A seventeen year old girl with known $\mathrm{Hb}$ SS disease was admitted with a three day history of colicky ab- 


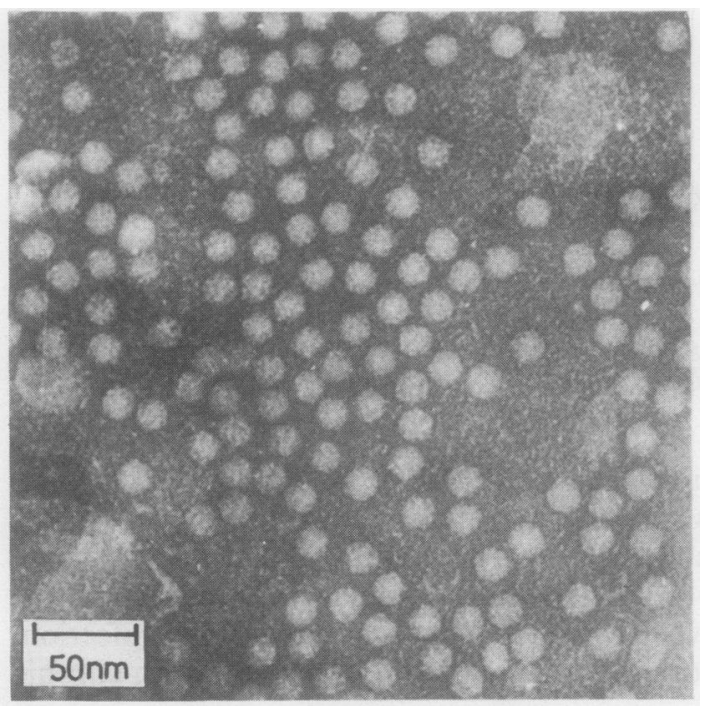

Fig. 2 Parvovirus particles in 10 1 l sample of patient serum. $\times 236800$.

dominal pain, fever, and vomiting. On examination she had a temperature of $38.5^{\circ} \mathrm{C}$ and was jaundiced. There were no other abnormal physical findings. Her haemoglobin concentration, usually $6.5 \mathrm{~g} / \mathrm{dl}$, was $6.0 \mathrm{~g} / \mathrm{dl}$ and reticulocyte count, usually $16 \%$, was $0.5 \%$. She remained febrile for several days and her haemoglobin concentration fell to $5.0 \mathrm{~g} / \mathrm{dl}$ (Fig. 3). She was transfused and made an uneventful recovery. Routine bacteriological and virological investigations yielded negative results, but parvovirus particles were detected in her blood by electronmicroscopy.

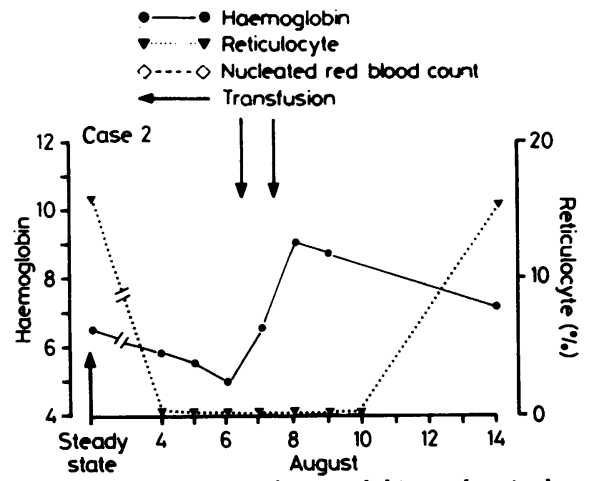

Fig. 3 Case 2. Change in haemoglobin and reticulocyte profile during aplastic crisis.

CASE 3

A twelve year old girl with known Hb SC disease was admitted to hospital with a seven day history of fever and a worsening cough, which was accompanied by purulent blood stained sputum and pleuritic pain. On examination she was pale and febrile with signs of right basal consolidation. Lobar pneumonia was confirmed on chest $\mathrm{x}$-ray. On admission her haemoglobin, which had previously been $11.6 \mathrm{~g} / \mathrm{dl}$, was $10.9 \mathrm{~g} / \mathrm{dl}$ and the reticulocyte count, previously $13 \%$, was $1.5 \%$. A pneumococcal infection was suspected, and she was treated with erythromycin as she had a history of allergy to penicillin. Chloroamphenicol was added after $\mathbf{4 8}$ hours as she failed to respond to initial treatment. Her fever and other physical signs then rapidly resolved. During this recovery period there was a considerable fall in haemoglobin concentration to $6.4 \mathrm{~g} / \mathrm{dl}$. Platelets fell to a low of $96 \times 10^{9} / 1$. Fig. 4 shows the subsequent course. During this period there was no increase in splenic size. Recovery from this phase was associated with a severe reticulocytosis.

No evidence of pneumococcal infection was found, and the pneumonia was shown to be due to $M y$ coplasma pneumoniae infection. In addition, parvovirus IgM was evident in the sample taken on the day of admission, showing that this child had a concurrent $M$ pneumoniae and parvovirus infection.

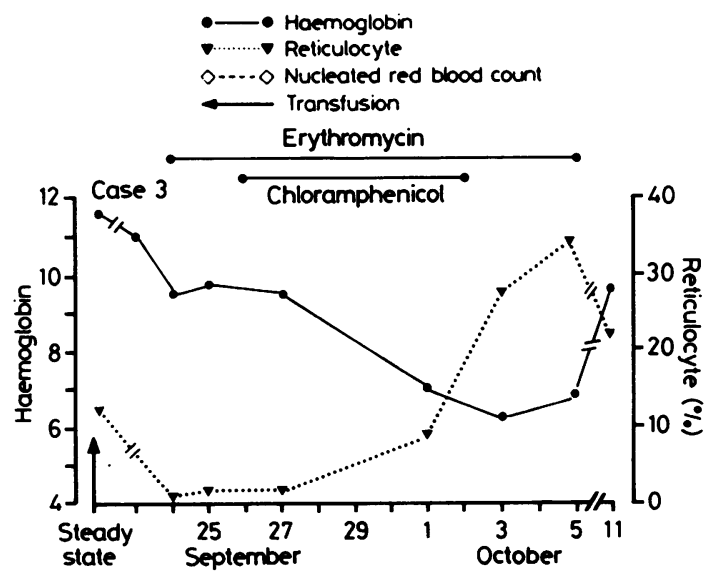

Fig. 4 Case 3. Change in haemoglobin and reticulocyte profile during aplastic crisis.

CASE 4

A six month old child with known $\mathrm{Hb}$ SC disease was admitted to hospital with a two day history of fever. On examination he had a temperature with enlarged tonsils and bulging red tympanic membranes. The liver was palpable, but the spleen was not enlarged. On admission his haemoglobin concentration, usually $8.2 \mathrm{~g} / \mathrm{dl}$, was $9.4 \mathrm{~g} / \mathrm{dl}$ and reticulocyte count, usually $13 \%$, was $3 \%$. He was treated with penicillin for a suspected bacterial infection and after a considerable improvement over forty eight hours he suddenly became drowsy. At that time his haemoglobin concentration was $4.2 \mathrm{~g} / \mathrm{dl}$ and reticulocyte count $0.2 \%$. There was no increase in liver or spleen size. The 

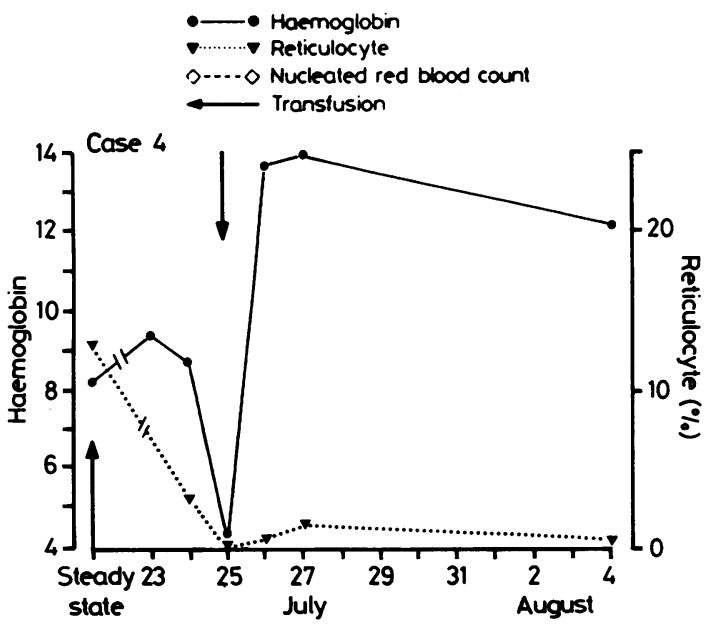

Fig. 5 Case 4. Changes in haemoglobin and reticulocyte profile during aplastic crisis.

platelet count fell to $85 \times 10^{9} / 1$. He was immediately transfused. Fig. 5 shows the subsequent course.

In spite of extensive microbiological investigations, including blood, throat, stools, urine, and cerebrospinal fluid culture, no likely bacterial agent was found. Standard viral cultures and serological tests yielded negative results. Parvovirus IgG and IgM were not detected in serum taken two weeks after the aplastic crisis.

\section{CASE 5}

A twenty two year old man with known thalassaemia intermedia who had had his spleen removed at the age of seventeen was admitted to hospital with a three week history of fever, haematuria, dysuria, and loin pain. On admission he was febrile $\left(39 \cdot 2^{\circ} \mathrm{C}\right)$ with right hypochondrial and loin tenderness. His haemoglobin concentration, which was usually $8.4 \mathrm{~g} / \mathrm{dl}$, was $7.2 \mathrm{~g} / \mathrm{dl}$ with a reticulocyte count of $11 \%$ and a total nucleated red count of $36.2 \times 10^{9} / 1$. He was initially treated with cefuroxime. A strain of Escherichia coli sensitive to this antibiotic was isolated from the blood and urine. The patient's temperature, however, failed to settle, and gentamicin was added. On the fourth day of admission his haemoglobin concentration dropped to $4.9 \mathrm{~g} / \mathrm{dl}$, the reticulocyte count to $1 \%$, and total nucleated red count to $1.1 \times 10^{9} / 1$ (Fig. 6). He was transfused and, although his urinary infection responded, his subsequent course was complicated by a haemolytic transfusion reaction caused by anti-E and anti-S. Parvovirus specific IgG was not detected in blood taken eight months after the crisis. Two brothers living in the same home also had no clinical or serological evidence of previous parvovirus infection.

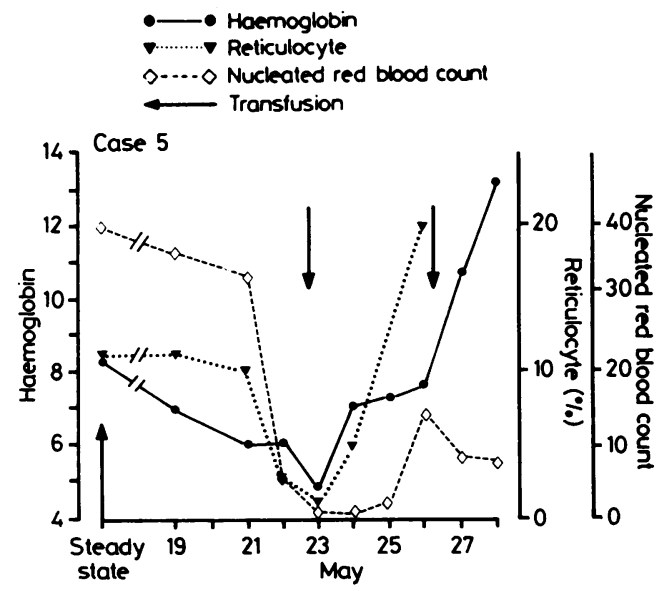

Fig. 6 Case 5. Changes in haemoglobin, reticulocyte, and nucleated red cell profile during hypoplastic crisis.

\section{Discussion}

Aetiologically, a wide variety of bacterial agents have been implicated in the aplastic crisis, which may complicate sickle cell anaemia. ${ }^{4-6}$ The importance of these findings, however, was called into question when Pattison et al showed that the human parvovirus could cause the aplastic crisis. ${ }^{1}$ Evidence has subsequently accumulated, indicating the wide geographical distribution of parvovirus infection and its close association with aplastic crisis in various haematological conditions. ${ }^{7}$ Indeed, the association has recently been shown to be so common that it has been suggested that a single agent, the parvovirus, may start the aplastic process. ${ }^{3}$

Serjeant ${ }^{2}$ showed that parvovirus was not the unique cause of aplastic crisis: one of his patients had a pneumococcal infection but no evidence of previous or concurrent parvovirus infection. The aetiology of the five cases reported here supports the general belief that parvovirus is the common, but not the only, cause of aplastic crisis in sickle cell anaemia. Three of our patients had unequivocal evidence of infection with this virus. In two patients parvovirus particles were seen in large numbers in the patient's blood and in the third parvovirus specific IgM was detected. This patient also had a high rise in antibody to $M$ pneumoniae, indicating a dual infection.

The two remaining cases, however, do not seem to be associated with parvovirus. The six month old child (case 4) had clinical evidence of middle ear infection and had a response to benzyl penicillin, features consistent with streptococcal or pneumococcal acute otitis media, although routine microbiological 
investigations did not indicate an aetiological agent. Case 5 had clear evidence of $E$ coli septicaemia associated with a urinary tract infection. Neither of these two patients had evidence of parovirus infection, using tests with a high degree of sensitivity and specificity for this agent.

We examined the clinical and haematological findings in these five cases for features that would distinguish those precipitated by a parvovirus infection from those unrelated to infection with this agent. There is some evidence to suggest that such distinction may be possible. A very rapid drop in haemoglobin concentration at the time of maximum reticulocytopenia was an important feature in the two patients (cases 4 and 5) without parvovirus infection; this contrasted with the slow but steady fall in the three other patients. On the other hand, the reticulocytopenia was less severe in case 5 , perhaps meriting the description hypoplastic rather than aplastic crisis. This less severe reticulocytopenia and the continuing presence of nucleated red cells in the peripheral circulation are consistent with splenectomy. Thus some difference in the haematological pattern is distinguishable, suggesting that when any deviation from the well recognised pattern of "aplastic" crisis associated with parvovirus is detected another causal agent should be considered.

These results are consistent with the view that parvovirus is a common, and perhaps the commonest, aetiological agent in the induction of aplastic and hypoplastic crises in sickle cell anaemia, but that other microbial agents can also initiate a similar crisis. Patients who have experienced such crises without parvovirus infection will be susceptible to a subsequent aplastic state if exposed to parvovirus infec- tion. A second attack of aplasia is unusual, however, and patients with sickle cell anaemia who acquire parvovirus infection do not always develop aplastic crisis. ${ }^{8}$ These results emphasis the importance of monitoring reticulocyte counts in patients with chronic haemolysis and acute infection.

We thank Dr M Brozovic for her help and Miss MP Fielding for preparing the manuscript.

\section{References}

${ }^{1}$ Pattison JR, Jones SE, Hodgson J, et al. Parvovirus infections and hypoplastic crisis in sickle cell anaemia. Lancet 1981:i:664-5.

${ }^{2}$ Serjeant GR, Topley JM, Mason K, et al. Outbreak of aplastic crisis in sickle cell anaemia associated with parvovirus-like agent. Lancet 1981:ii:595-7.

${ }^{3}$ Mortimer PP. Hypothesis: the aplastic crisis of hereditary spherocytosis is due to a single transmissible agent. J Clin Pathol 1983:36:445-8.

${ }^{4}$ Chernoff AI, Josephson AM. Acute erythroblastopenia in sickle cell anaemia and infectious mononucleosis. Am J Dis Child 1951:82:310-22.

${ }^{5}$ Alegas H, Papadaki E, Constantinides B. Salmonella septicaemia and aplastic crisis in a patient with sickle cell anaemia. Acta Pediatr 1961:50:517-21.

${ }^{6}$ Charney E, Miller G. Reticulocytopenia in sickle cell disease. Am $J$ Dis Child 1964:107:450-5.

${ }^{7}$ Davis LR. Annotation aplastic crisis in haemolytic anaemias: the role of a parvovirus-like agent. Br J Haematol 1983:55:391-3.

${ }^{8}$ Anderson MJ, Davis LR, Hodgson J, et al. Occurrence of infection with a parvovirus-like agent in children with sickle cell anaemia during a two year period. J Clin Pathol 1982:35:744-9.

Requests for reprints to: Dr AI Brownell, Department of Haematology, Central Middlesex Hospital, Acton Lane, London NW10 7NS, England. 
Fundamentals of Skin Biopsy. June K Robinson. (Pp 124; £24.) 1986. Year Book Medical Publishers Inc. ISBN 0-8151-7312-1.

This A4 sized paper back is written by someone who does not state her qualifications and training in this field. This is important at a time when young dermatologists in the United Kingdom are being encouraged to take a greater interest in dermatological surgery. The borderline between dermatological and plastic surgery is poorly defined, and in this particular text there are a surprising number of black and white illustrations (some of indifferent quality) of facial procedures, including procedures around the lips and eyelid. Not all dermatologists would feel that these belong in such a text.

After three chapters on biopsy planning and anaesthesia the author describes punch, currettage, and elliptical excision biopsy techniques-in this order. This no doubt reflects the American enthusiasm for punch rather than elliptical biopsies. There then follow three useful sections on wound closure, wound improvement technique, and dressings, which include tables that are duplicated 40 pages on at the end of the book.

At $£ 24$ the book is relatively expensive. Young dermatologists and others who need to do good quality skin biopsies would learn as much, and probably considerably more, by spending one or two afternoons in an outpatient session with a plastic surgeon. There is little in the book of direct interest or importance to routine pathologists.

RONA M MACKIE

Biochemical Values in Clinical Medicine. 7th ed. RD Eastham. (Pp 473; £12.50.) Wright. 1985.

The last edition of this very useful guide to biochemical tests and interpretation was published in 1978. As a result of advances in knowledge and improved technology the pocket size edition has had to give way to a more substantial volume.

The introduction of a coding system indicating those tests required in an emergency, those done routinely, specialised tests and their cost, and those that are now obsolete has greatly added to its value.

This book will be of use as a rapid aide memoire to clinicians using the laboratory and to the chemical pathologist.

BRENDA SLAVIN

Notices

Fourth International Symposium on Morphometry in Morphological diagnosis

\section{Royal Society of Medicine, September 10-12, 1986}

\section{ACP Symposium}

\section{THE FUTURE OF PATHOLOGISTS IN AN AGE OF COST CONTAIN- MENT AND TECHNOLOGICAL CHANGE}

The Association of Clinical Pathologists is organising a two day symposium with the above title to be held at the Barbican Centre, London on the afternoon of Thursday 16 and Friday 17 October 1986.

The Thursday session will cover the policy of the DHSS and its impact on the service specialities, the allocation of resources, the management of laboratories, and the need for information technology and performance indicators. The Friday morning session will cover future trends dealing with each discipline in turnnamely, histopathology, clinical chemistry, microbiology, haematology, and forensic pathology. There will also be sessions dealing with the future of private practice and on the effects of training, teaching and research. Dr H Derman will speak on the changing role of the pathologist in America and the programme will probably include a similar lecture dealing with pathology in Europe.

Speakers from the United Kingdom will include Professor ED Acheson, Chief Medical Officer, DHSS; Professor B Clayton, President of the Royal College of Pathologists; Professor R Dyson, University of Keele; Mr B Edwards, Trent Regional General Manager; Dr PM Emerson, Consultant Haematologist; Professor FV Flynn, Consultant Chemical Pathologist; Dr AC Hunt, Consultant Histopathologist; $\mathrm{Dr} \mathbf{H}$ Lommel, World Association of the Societies of Pathology; Dr AR Morley, Consultant Histopathologist; Dr JWG Smith, Director of the Public Health Laboratory Service; Mr C Spry, District General Manager, Newcastle Health Authority; Dr EW Walton, Consultant Histopathologist; and Mr GJ Wasserman, Assistant Under Secretary of State at the Home Office.

Further details may be obtained from: the Association of Clinical Pathologists, 57 Lower Belgrave Street, London SW1W 0LR.
Although covering image analysis using large systems, many of the contributions will describe the use of small micro based systems suitable for use in a district general hospital. One session will be devoted to flow cytometry. The emphasis throughout will be on clinical applications and clinical usefulness. The programme includes invited expert guest speakers: Bahr (USA); Watson (UK); Ploem (Netherlands); Wied (USA); Aver (Sweden); Baak (Netherlands); Stenqvist (Sweden); and Collan (Finland).

There will also be a wide range of proferred papers and poster demonstrations, particularly on the applications of morphometry to gut, bone, breast, lymphoreticular and urogenital pathology. A pleasing feature of the proferred papers are the contributions correlating structure and function, which is an ideal aim for clinical pathologists.

A limited number of places now remain for attendance at the symposium. These will be allocated on a strictly first come, first served basis.

Further details may be obtained from: Miss Elaine Gill, Gill Medical, 429 Tamworth Road, Long Eaton, Nottingham NG10 3JT, England.

\section{ACP Locum Bureau}

The Association of Clinical Pathologists runs a locum bureau for consultant pathologists.

Applicants with the MRC Path who would like to do locums and anyone requiring a locum should contact $\mathrm{Dr}$ David Melcher, Histopathology Department, Sussex County Hospital, Eastern Road, Brighton BN2 5BE.

\section{Correction}

On page 121 of $J$ Clin Pathol 1986;39 the designations of the authors were incorrect. Dr Cubitt works for the Department of Microbiology, Central Middlesex Hospital and Alison Brownell for the department of haematology, Central Middlesex Hospital. 